\title{
BENTUK PERLAKUAN PATRON TERHADAP KLIEN DALAM PERDAGANGAN KAYU MANIS DI PASAR NAGARI KABUPATEN TANAH DATAR
}

\author{
Yeni Erita \\ Program Studi Pendidikan Geografi STKIP PGRI Sumatera Barat \\ Email: anwaryenierita@yahoo.co.id
}

\begin{abstract}
The purpose of this study was to determine and analyze any form of treatment patron of the client in the cinnamon trade in Nagari Pasar Tanah Datar. The research is a qualitative research, the naturalistic or natural, it is done on a particular natural background, and has a particular case.

The results of the research are: 1). Rooted historically to trading activity in the village market, especially with the Client Patron export commodities traders. 2). Having a wide network klientisasi in control of the business, has the ability to build reciprocity to strengthen social insurance with business partners. 3). Patron business network and market traders in villages Clients who trade export crops can be used as a base to develop the agricultural product processing industry whose market is wide open in the ASEAN and China. 4). The creation of a network of business groups klientisasi to village markets can be a forerunner to form a business network Minangkabau to compete with China's business network, in exploiting investment opportunities provided by the government of West Sumatra. 5). With the capability of reciprocity and social insurance held so far, can create business linkages (business leakage) with groups of businesses along the corridor of Sumatra.
\end{abstract}

Keywords: Treatment, clients, cinnamon

\begin{abstract}
Abstrak
Tujuan penelitian ini adalah untuk mengetahui dan menganalisis bentuk perlakuan patron terhadap klien dalam perdagangan kayu manis di Pasar Nagari Kabupaten Tanah Datar. Jenis penelitian ini adalah penelitian kualitatif, yang bersifat naturalistik atau alamiah, yang dilakukan pada suatu latar alamiah tertentu, dan memiliki kasus tertentu.

Hasil penelitian antara lain: 1). Mengakar secara historis kepada aktifitas perdagangan di pasar nagari, terutama Patron dengan Klien pedagang komoditi ekspor. 2). Memiliki jaringan klientisasi yang luas dalam menguasai bisnis, memiliki kemampuan membangun resiprositas untuk memperkuat asuransi sosial dengan mitra bisnis. 3). Jaringan bisnis Patron dan Klien pedagang di pasar nagari yang memperdagangkan tanaman eksport dapat dijadikan basis untuk mengembangkan industri pengolahan produk pertanian yang pasarnya terbuka lebar di ASEAN dan China. 4). Terciptanya jaringan klientisasi kelompok bisnis sampai ke pasar nagari dapat menjadi cikal bakal untuk membentuk jaringan bisnis Minangkabau untuk bersaing dengan jaringan bisnis China, dalam memanfaatkan peluang investasi yang diberikan pemerintah Sumatera Barat. 5). Dengan kemampuan resiprositas dan asuransi sosial yang dimiliki selama ini, dapat membuat keterkaitan bisnis (business leakage) dengan kelompok-kelompok bisnis di sepanjang koridor Sumatera.
\end{abstract}

Kata Kunci: Perlakuan, klien, kayu manis 


\section{PENDAHULUAN}

Pasar merupakan pertemuan antara penjual dengan sipembeli. Mayarakat Tanah Datar mempunyai pasar yang dikenal dengan pasar nagari. Pasar nagari yang paling banyak memperdagangkan kayu manis adalah pasar nagari Baso, Sungai Tarab, dan Tabek Patah. Karakteristik pedagang pengumpul kayu manis di pasar nagari dapat pula ditinjau dari segi pola pemukiman, sumber modal, luas lahan, dan makna berdagang bagi mereka.

Pekerjaan berdagang kayu manis sebagai prestise dan memupuk modal budaya masyarakat mereka. Berbeda dengan pedagang tanpa modal yang lebih dikenal dengan pemberi isyarat atau cingkariak, mereka umumnya bermukim di pinggiran nagari, sumber modal sebagian besar merupakan modal sendiri dan dari pinjaman Inang-inang, tetapi makna berdagang bagi mereka adalah untuk melakukan diversifikasi usaha dalam kerangka katup pengaman ekonomi rumahtangga mereka.

Kedudukan dan status sosial sebuah keluarga di nagari Salimpaung sebagian dilihat dari seberapa besar luas lahan kayu manis yang dimiliki oleh keluarga tersebut. Semakin besar luas lahan kayu manis yang dimiliki, sebuah keluarga semakin dipandang tinggi keluarga tersebut di tengah masyarakat, walaupun menurut stratifikasi sosial yang didasarkan atas jabatan adat dan orang asa nagari, keluarga itu berasal bukan dari orang asa nagari. Artinya, luas kepemilikan lahan kayu manis merupakan salah satu cara untuk melakukan mobilitas antar kelas di tengah masyarakat.

Pedagang kayu manis yang tanpa modal pada umumnya adalah mereka yang berasal dari orang dangau (sebutan bagi orang pendatang) dahulunya dengan luas lahan sawah yang sempit. Sedangkan pedagang yang bermodal besar adalah orang asa nagari dengan luas lahan sawah dan ladang kayu manis yang relatif luas, tetapi ikut terjun menjadi pedagang semata-mata lebih melihat pada besarnya keuntungan yang diperoleh. Pedagang bermodal 
besar ini bersifat lebih rasional dan berorientasi mencari keuntungan (profit motive). Sangat berbeda dengan pedagang kayu manis yang berasal dari orang dangau yang lebih mengutamakan dan tetap menjaga trust dengan petani kayu manis yang menjadi pelanggannya. Dapat dilihat pada tabel di bawah ini:

\section{Tabel 1.1 Tipologi Pedagang Pengumpul Kayu Manis di Pasar Nagari}

\begin{tabular}{|c|c|c|c|c|c|c|}
\hline \multirow[t]{2}{*}{ No } & \multirow{2}{*}{$\begin{array}{l}\text { Kategori } \\
\text { Pedagang }\end{array}$} & \multirow{2}{*}{$\begin{array}{l}\text { Pola } \\
\text { Pemukiman }\end{array}$} & \multirow{2}{*}{$\begin{array}{l}\text { Sumber } \\
\text { Modal }\end{array}$} & \multicolumn{2}{|c|}{ Luas Lahan } & \multirow[t]{2}{*}{ Makna Berdagang } \\
\hline & & & & $\begin{array}{l}\text { Sawah } \\
\text { (ha) }\end{array}$ & $\begin{array}{l}\text { Ladang } \\
\text { (ha) }\end{array}$ & \\
\hline 1. & $\begin{array}{l}\text { Pedagang } \\
\text { Modal } \\
\text { Kuat } \\
\end{array}$ & $\begin{array}{lr}\begin{array}{l}\text { Pusat } \\
\text { elite }\end{array} & \begin{array}{r}\text { nagari, } \\
\text { (orang }\end{array} \\
\text { asa) } & \\
\end{array}$ & Sendiri & $\geq 1$ & $>0,5$ & $\begin{array}{l}\text { Prestise/akumulasi } \\
\text { modal budaya dan } \\
\text { finansial }\end{array}$ \\
\hline \multirow[t]{2}{*}{2.} & \multirow{2}{*}{$\begin{array}{l}\text { Pedagang } \\
\text { tanpa } \\
\text { Modal/pe } \\
\text { mberi } \\
\text { isyarat/ci } \\
\text { ngkariak }\end{array}$} & \multirow{2}{*}{$\begin{array}{l}\text { Pinggiran } \\
\text { nagari, suku } \\
\text { pendatang }\end{array}$} & $\begin{array}{l}\text { Pedagang } \\
\text { besar }\end{array}$ & $0,5-1$ & $0,5-1$ & \multirow{2}{*}{$\begin{array}{lr}\begin{array}{l}\text { Diversifikasi } \\
\text { pencaharian } \\
\text { pengaman) }\end{array} & \text { (katup } \\
\end{array}$} \\
\hline & & & $\begin{array}{l}\text { Inang- } \\
\text { inang }\end{array}$ & $0-0,5$ & $0-0,5$ & \\
\hline 3. & $\begin{array}{l}\text { Pedagang } \\
\text { besar } \\
\text { (palantua } \\
\text { k) }\end{array}$ & Supra nagari & $\begin{array}{l}\text { Sendiri/pin } \\
\text { jaman dari } \\
\text { bank, dan } \\
\text { pemerintah }\end{array}$ & - & - & $\begin{array}{l}\text { Akumulasi modal } \\
\text { (profit oriented) }\end{array}$ \\
\hline
\end{tabular}

Sumber: Hasil Penelitian, 2006-2010 (data diolah)

Berdasarkan tabel di atas, terlihat bahwa pedagang dengan modal kuat pada umumnya bermukim di pusat nagari dan mereka menjadikan besarnya kapasitas perdagangan kayu manis ini di pasar nagari Salimpaung, ini disebabkan oleh beberapa hal; pertama kayu manis merupakan komoditi andalan bagi ekonomi rumahtangga petani berlahan sawah sempit dan pedagang tanpa modal di nagari Salimpaung. Kedua, potensi luas lahan kayu manis yang lebih besar di bandingkan dengan potensi yang dimiliki oleh nagari lain. Ketiga berkaitan dengan tradisi adat perkawinan masyarakat setempat, telah menempatkan tanaman kayu manis sebagai tanaman adat dan simbol bagi kekuatan ekonomi masyarkat nagari Salimpaung. 
Jika dilihat lebih dalam, sebenarnya pengusahaan dan penguasaan luas lahan kayu manis di sebuah nagari pada mulanya dibuka oleh orang yang bukan asal nagari atau "orang dangau" (sebutan bagi orang pendatang), tetapi setelah berkembangnya jumlah penduduk, maka orang dangau ini kemudian lebih banyak menguasai luas lahan kayu manis tetapi lebih sedikit menguasai luas lahan sawah. Dalam perkembangan selanjutnya, karena terbatasnya luas lahan sawah yang dimiliki pada umumnya merekalah yang menjadi pedagang kayu manis di pasar nagari. Namun karena perdagangan kayu manis ini banyak memberikan keuntungan bagi pedagang kayu manis, maka sebagian besar orang asa nagari ikut pula menjadi pedagang kayu manis dengan modal yang lebih besar.

Jadi sikap pedagang kayu manis tanpa modal yang lebih mengutamakan terciptanya saling percaya (trust building) antara pedagang dan petani kayu manis di pasar nagari adalah karena secara historis, posisi dan kedudukan mereka merupakan orang dangau dan ditambah lagi dengan kenyataan bahwa, bagi mereka berdagang kayu manis di pasar nagari merupakan salah satu cara untuk menambah pendapatan di luar sektor pertanian. Dengan berdagang kayu manis mereka memperoleh pendapatan tambahan yang cukup besar untuk setiap kali dibukanya pasar nagari. Dua alasan itulah kenapa pedagang kayu manis pada kelompok pedagang tanpa modal (pemberi isyarat) lebih memperhatikan dan memelihara relasi sosial dengan mitra dagangnya baik dengan petani sendiri maupun dengan sesama pedagang.

\section{METODE PENELITIAN}

Penelitian ini merupakan penelitian sosiologi dengan bidang kajian sosiologi ekonomi. Lazimnya sebuah penelitian, khususnya bidang kajian sosiologi ekonomi, penelitian ini memiliki ciri tertentu yang menjadi ciri 
khas dari penelitian sosiologi, yakni merupakan penelitian kualitatif, yang bersifat naturalistik atau alamiah, yang dilakukan pada suatu latar alamiah tertentu, dan memiliki kasus tertentu.

Berdasarkan pertanyaan penelitian yang diajukan, maka untuk mendekati subjek penelitian dan menciptakan pemahaman yang disepakati bersama antara tineliti dengan peneliti maka studi ini menggunakan pendekatan multi metode guna mendekati persoalan yang diajukan. Pilihan metodologi penelitian juga metode penelitian sekaligus menentukan pilihan paradigma dalam penelitian ini.

Penelitian ini, secara paradigmatik, memposisikan diri pada paradigma nonpositivistik, yang muncul sebagai kritik atas paradigma positivistik, yang menganggap bahwa realitas di luar sana sepenuhnya dikendalikan oleh hukum-hukum alam, sehingga tugas peneliti adalah menemukan dan merumuskan hukum-hukum alam yang bersifat objektif dan universal. Akan tetapi paradigma ini telah dianggap memiliki kelemahan, karena pada dasarnya indra manusia terbatas dan tidak mampu melihat dan memahami realitas keseluruhan secara utuh (Guba dan Lincoln, 2000; Lubis, 2004).

Dengan demikian dalam pandangan non-positivistik, karena terdapatnya keterbatasan indera manusia untuk memahami realitas sepenuhnya, akibatnya setiap peneliti melihat dan memahaminya secara berbeda sesuai dengan sudut pandangnya yang subyektif (Guba dan Lincoln, 2000). Sehinggga, sebagai penelitian yang memposisikan diri pada paradigma non-positivistik, tujuan penelitiannya tidak diarahkan pada penemuan hukum-hukum atau teori yang berlaku secara universal dan dapat digeneralisir, tetapi diarahkan pada pengembangan teori yang mampu memberikan pemahaman yang mendalam tentang subjek kajiannya, sekaligus menemukan berbagai variasi yang terjadi di dalamnya (Guba, 1990 dalam Lubis, 2004). 
Pilihan paradigma membimbing peneliti untuk melihat realitas yang diteliti serta bagaimana prosedur penelitian dilakukan (Lubis, 2004). Guba dan Lincoln (2000, 163-186), mengemukakan empat paradigma utama yang bersaing dalam ilmu pengetahuan dengan berbagai asumsi-asumsi yang mendasarinya, yaitu positivisme, post-positivisme, teori kritis (critical theory), dan paradigma konstruktivisme (constructivism).

\section{PEMBAHASAN}

Pada saat ini pedagang kayu manis merupakan kelompok elite ekonomi di tengah masyarakat nagari. Keuntungan yang mereka peroleh dari perdagangan kayu manis disamping telah digunakan untuk membangun simbol-simbol status sosial seperti membangun rumah yang lebih megah, mengangkat penghulu baru bahkan menjadi penghulu, juga telah diakumulasikan guna menjalin jaringan kerja yang lebih luas dengan para pedagang besar di tingkat supra nagari.

Kenyataan saat sekarang kebanyakan pedagang di pasar nagari merupakan kelompok pedagang tanpa modal, hal itu disebabkan oleh sistem tata niaga kayu manis yang dikuasai oleh pedagang dari etnis China. Para pedagang kayu manis di pasar nagari yang ditemui di daerah penelitian, sebagian besar sudah pernah menjadi pedagang besar dan pedagang pengumpul bagi eksportir, tetapi karena politik perdagangan eksportir yang cenderung menunda pembayaran setelah kayu manis berikutnya dikirim (dikirim 2 kali di bayar 1 kali), maka hanyalah pedagang yang bermodal kuat dan berlapis yang mampu menjadi kaki tangan eksportir.

Upaya perdagangan yang dilakukan eksportir Cina untuk menekan pedagang tingkat pasar nagari untuk memutuskan mata rantai pemasaran kayu manis merupakan politik perdagangan mereka untuk tetap mendominasi perdagangan kayu manis di Provinsi Sumatera Barat. Hanya dengan menciptakan jaringan kerja dengan satu pedagang kabupaten saja, 
memungkinkan eksportir dapat mengendalikan harga kayu manis di tingkat pedagang pasar nagari. Semakin ke bawah jumlah pedagang kayu manis semakin banyak, sebaliknya semakin ke atas pedagang kayu manis semakin sedikit dan semakin terjadi monopsoni tersembunyi oleh eksportir.

Hubungan pedagang pengumpul di pasar nagari dengan pedagang tingkat kabupaten lebih berbentuk pada hubungan Patron-klien. Pedagang pengumpul tingkat nagari dan kecamatan merupakan pedagang yang menjadi perpanjangan tangan pedagang tingkat kabupaten. Pedagang tingkat kabupaten (supra lokal) bertindak sebagai bapak buah (Patron) dan pedagang pengumpul di pasar nagari bertindak sebagai anak buah (klien), yang sebagian memperoleh pinjaman modal untuk membeli kayu manis kepada petani, kemudian kayu manis yang dibeli oleh pedagang pengumpul tingkat nagari akan dijual kembali kepada Patronnya dengan harga yang telah disepakati sebelumnya.

Seorang Patron memiliki 5 sampai 7 orang agen di pasar-pasar nagari, mereka inilah yang dikategorikan dalam penelitian ini dengan pedagang modal kecil dan pedagang tanpa modal (pemberi isyarat). Para pedagang yang membentuk hubungan Patron-klien inilah yang membentuk jaringan (network) berkelompok. Artinya ada kelompok-kelompok (clique members) pedagang kayu manis untuk menghadapi pembelian kayu manis petani di pasar nagari. Kelompok-kelompok pedagang inilah yang melakukan transaksi di pasar dengan menekan harga serendah mungkin, agar memperoleh keuntungan besar, dengan cara membuat penawaran berkelompok.

Dalam wilayah penelitian, pedagang tingkat kabupaten yang bertindak sebagai Patron diantaranya H. WN (56 Tahun), Guru/Eti (52 tahun), CN (54 tahun), WR (38 Tahun), H. KTR (68 Tahun) masing-masing mereka memiliki perpanjangan tangan (klien) sebagai pedagang pengumpul 
kayu manis di setiap pasar nagari. Para pedagang pengumpul pasar nagari inilah yang sebagian diberi modal untuk membeli kayu manis di pasar-pasar nagari kepada petani. Meskipun demikian, seorang pedagang pengumpul pasar nagari terkadang bukan hanya menjadi anggota dari satu clique members saja, tetapi lebih dari satu, sangat tergantung kepada bagaimana Patronnya menjaga hubungan dengan kliennya dan sebaliknya.

Kelanggengan bentuk hubungan Patron-klien diantara pedagang kayu manis ini sangat tergantung kepada pemupukan saling percaya (trust) diantara mereka. Kesetiaan seorang klien sangat tergantung kepada pertama: seberapa besar modal untuk membeli kayu manis di pasar nagari pada setiap kali dibukanya pasar nagari dapat diberikan oleh Patronnya, semakin besar pinjaman modal dapat diberikan, maka semakin terikat seorang klien kepada Patronnya dan semakin kokoh jalinan perdagangan mereka. Kedua: seberapa besar selisih margin yang diberikan oleh Patron terhadap kliennya, semakin besar marginnya semakin besar keuntungan yang akan diperoleh klien dalam pembelian kayu manis kepada petani, sebab para klien ini harus juga memelihara hubungan baik (klientisasi) dalam bentuk relasi sosial dengan petani kayu manis, agar petani kayu manis terikat dan mau menjual kayu manisnya kepada klien ini, dengan cara membeli kayu manis dengan harga yang wajar menurut petani. Bahkan dalam hubungan ini juga terjadi permainan aspek ruang antara pedagang dengan petani kayu manis. Ketiga: seberapa besar perhatian Patron yang diberikan kepada kliennya dalam menjaga hubungan sosial (social relationship) mereka dengan memberikan hadiah-hadiah pada saat hari-hari besar keagamaan, seperti pembagian infak, zakat, daging korban, kado pesta pernikahan anak klien, bantuan pembangunan mesjid dan mushalla di kampung klien, dan kunjungankunjungan pada saat-saat waktu tertentu untuk memberikan penguatan kepada kedudukan sosial para klien (klientisasi). 
Tabel 1.2 Jaringan Patron-klien Pedagang Kayu Manis di Pasar Nagari

\begin{tabular}{|c|l|r|r|r|r|r|r|}
\hline No & $\begin{array}{l}\text { Pedagang Tingkat } \\
\text { Kabupaten sebagai } \\
\end{array}$ & \multicolumn{1}{|c|}{$\begin{array}{c}\text { Jumlah Klien di Pasar Nagari } \\
\text { Paso }\end{array}$} & $\begin{array}{c}\text { Tabek } \\
\text { Patah } \\
(6)\end{array}$ & $\begin{array}{c}\text { Salimpaung } \\
(14)\end{array}$ & $\begin{array}{c}\text { Rao- } \\
\text { Rao } \\
(1)\end{array}$ & $\begin{array}{c}\text { Sungai } \\
\text { Tarab } \\
(4)\end{array}$ & \\
\hline 1. & H. WN (Simpuruik) & 15 & 4 & 9 & 1 & 2 & 31 \\
\hline 2. & WR (Salimpaung) & 8 & 0 & 0 & 0 & 0 & 8 \\
\hline 3. & $\begin{array}{l}\text { H. Guru/Hj. Eti } \\
\text { (Sungayang) }\end{array}$ & 0 & 0 & 0 & 0 & 0 & 0 \\
\hline 4. & CN (Payakumbuh) & 2 & 4 & 4 & 0 & 0 & 10 \\
\hline 5 & H. KTR (Jati) & 0 & 0 & 0 & 0 & 0 & 0 \\
\hline 6. & MS (Lintau) & 0 & 0 & 0 & 0 & 0 & 0 \\
\hline 7. & UD.Misril & 0 & 0 & 2 & 0 & 1 & 3 \\
\hline
\end{tabular}

Sumber: Hasil Penelitian, 2010 (data diolah)

Berdasarkan tabel di atas terlihat bahwa Patron yang paling besar jaringannya adalah H. WN (56 Tahun) dari Simpuruik Batu Sangkar, WR (38 Tahun) dari Nagari Salimpaung, dan CN (48 tahun) dari Payakumbuh. Jaringan kerja yang dibangun oleh $\mathrm{H}$. WN hampir mencakup semua pasar nagari, sedangkan CN (Payakumbuh) jaringan kerjanya hanya pada tiga pasar nagari yakni Baso, Tabek Patah, dan Salimpaung, untuk pasar nagari RaoRao dan Sungai Tarab dikuasai oleh H. WN dan UD. ML, WR (38 tahun) hanya memiliki jaringan kerja di pasar Baso, di pasar nagari lainnya, WR relatif kurang dipercayai karena dianggap sering mengecewakan kliennya, sehingga WR lebih banyak memperoleh kayu manis dari luar kabupaten Tanah Datar seperti di Baso, dan Matur kabupaten Agam.

Ada tiga orang Patron yang tidak mengaktifkan para kliennya pada saat penelitian dilakukan yakni H. Guru/Eti (52 tahun) dari Sungayang, H. KTR (68 Tahun) dari Jati Batu Sangkar, dan MS (54 tahun) dari Lintau, menurut para klien di pasar nagari yang pernah menjadi anggota kelompok mereka, Patron mereka tidak aktif karena sedang memiliki stok yang berlimpah di gudang mereka, dan untuk sementara menghentikan pembelian 
melalui para kliennya. Sehingga para klien ini beralih menjadi anggota Patron lainnya. Jadi, ada beberapa klien yang menjadi anggota dari dua atau lebih Patronnya. Artinya ikatan diantara Patron dan klien agak longgar dan sangat tergantung pada seberapa besar Patron mampu secara kontinu membeli kayu manis pada kliennya.

Menurut pengakuan bekas klien H. Guru/Eti di Pasar nagari Tabek Patah Dt. Rajo Sampono (73 Tahun), ia hanya sementara menjadi klien H. WN, menjelang H. Guru/Eti aktif kembali menerima kiriman (membutuhkan) kayu manis yang dikumpulkannya di Tabek Patah, sebab menurutnya $\mathrm{H}$. Guru/Eti lebih banyak memberikan kemudahan baginya dalam meminjam modal dan memberikan harga yang lebih baik ketimbang H. WN, seperti dikatakan Dt. Rajo Sampono " saya sulit lepas dari H. Guru/Eti karena merekalah yang membantu usaha saya sejak awal sehingga menjadi kokoh saat sekarang". Jadi keterikatan secara emosional (reciprositas mutualism) dengan Patronnya masih menjadi pertimbangan dalam membangun jaringan kerja, sekali pedagang pengumpul pasar nagari ini dikhianati, mereka tidak percaya kepada Patronnya, seperti yang dialami oleh WR di nagari Salimpaung.

Dengan adanya relasi sosial interpersonal terutama dalam bentuk klientisasi antara pedagang pengumpul pasar nagari dengan pedagang besar (supra lokal) di tingkat kabupaten yang membentuk hubungan Patron-klien (reciprocal mutualism) telah menyebabkan para pedagang pasar nagari memiliki kemapanan ekonomi yang lebih di tengah masyarakat nagari. Para pedagang pengumpul di pasar nagari ini telah menjadi kaum elite ekonomi nagari dengan membangun simbol-simbol, kedudukan dan posisi sosial mereka di tengah masyarakat nagari seperti titel Haji, Datuak atau Penghulu, membangun rumah toko permanen, donatur tetap di mesjid dan mushalla bahkan menjadi donatur untuk kegiatan pemuda seperti olahraga, dan 
kesenian. Kedudukan mereka sebagai orang kaya di nagari, telah menyebabkan mereka memiliki pengaruh besar dalam pengambilan keputusan yang menyangkut dengan kepentingan masyarakat nagari. Fenomena ini sesuai dengan yang diindikasikan oleh Evers (1994), bahwa pedagang dalam menghadapi petani di desanya menghadapi dilema tidak hanya berorientasi mengakumulasi modal tetapi juga harus menjaga citranya di tengah masyarakat dalam bentuk melakukan akumulasi modal budaya. Di samping itu pedagang juga harus berbagi keuntungan dengan masyarakat sekitarnya dalam bentuk memberi sumbangan atau menjadi donatur dalam berbagai kegiatan kampung (hubungan klientisasi). Namun dalam bertransaksi dengan petani, ekonomi moral pedagang terlihat "sangat tipis", sementara ekonomi moral petani lebih kental terlihat.

Bila dilihat dari lokasi tempat tinggal, mereka para pedagang pengumpul di pasar nagari yang semula adalah orang-orang dangau yang bermukim jauh dari pusat nagari, maka dengan pendapatan yang besar dari perdagangan kayu manis, para elite ekonomi baru ini membeli tanah untuk membangun rumahnya di pusat nagari dan dekat dengan pasar nagari. Bahkan mereka banyak menguasai lahan-lahan sawah dan ladang dengan sistem pagang gadai. Pada umumnya pedagang kayu manis di pasar nagari ini membangun rumah dan gudang kayu manisnya lebih dekat ke pinggiran jalan raya, agar aksessibilitas ke patronnya dapat berjalan dengan baik. Hal ini dapat dilihat pada tabel kedudukan dan posisi sosial pedagang dibawah ini:

Tabel 1.3 Kedudukan dan Posisi Sosial Pedagang Pengumpul Pasar Nagari di Tengah Masyarakat Nagari

\begin{tabular}{|l|l|c|c|c|c|}
\hline No & \multicolumn{1}{|c|}{ Pasar Nagari } & \multicolumn{2}{|c|}{ Jumlah Pedagang Memiliki Kedudukan dan } & Jumlah \\
\cline { 3 - 6 } & & $\begin{array}{c}\text { Datuak/ } \\
\text { pemangku } \\
\text { adat }\end{array}$ & Haji & $\begin{array}{c}\text { Mantan } \\
\text { Walinagari/ } \\
\text { Kepala Desa }\end{array}$ & \\
\hline 1 & Salimpaung & 3 & 4 & 0 & 7 \\
\hline 2. & Tabek Patah & 3 & 2 & 1 & 6 \\
\hline
\end{tabular}




\begin{tabular}{|l|l|c|c|c|c|}
\hline 3. & Baso & 1 & 3 & 0 & 4 \\
\hline 4. & Rao-Rao & 0 & 1 & 0 & 1 \\
\hline 5. & Sungai Tarab & 1 & 1 & 0 & 2 \\
\hline & Jumlah & 8 & 11 & 1 & 20 \\
\hline
\end{tabular}

Sumber: Hasil Penelitian, 2010 (data diolah)

Apabila dilihat per nagari, jumlah pedagang yang memiliki kedudukan dan posisi sosial politik di tengah masyarakat nagari sangat dominan, adalah di nagari Salimpaung, ada 7 orang (58 persen) pedagang pengumpul kayu manis di pasar nagari memiliki kedudukan dan posisi sebagai Datuak, dan Haji. Di nagari Tabek Patah terdapat 6 orang (100 persen) pedagang pengumpul pasar nagari memiliki simbol-simbol sosial ekonomi yang menguntungkan praktek bisnis mereka, karena mendapat kepercayaan dan kekuatan sosial dalam menghadapi petani kayu manis dalam transaksi kayu manis di pasar nagari. Di nagari Sungai Tarab ada 2 orang (50 persen) pedagang pengumpul yang memiliki gelar Haji, yang diyakini sumber kepercayaan masyarakat untuk menarik pelanggan petani kayu manis untuk mau menjual kayu manis kepada pedagang yang bertitel haji ini. Titel haji bagi pedagang memperlihatkan simbol-simbol sifat jujur, taat beribadah dan tidak akan mau melakukan penipuan terhadap mitra bisnisnya. Titel haji juga akan memberikan kedudukan sosial ekonomi mereka di tengah masyarakat tergolong kepada orang yang ekonominya mampu atau memiliki kekayaan yang berlebih dari masyarakat biasa. Sehingga, salah satu tanda sukses anggota masyarakat nagari adalah apabila sudah beribadah haji ke Mekah, apalagi bila pergi haji lebih dari sekali.

Jabatan Datuak dan pemangku adat serta titel haji merupakan simbolsimbol yang besar maknanya bagi pedagang pengumpul di pasar nagari untuk kontinuitas bisnis kayu manis mereka di tengah masyarakat nagari. Jabatan Datuak memiliki konsekwensi bahwa pedagang pengumpul memiliki 
keuntungan sosial ekonomi dalam bisnis, karena dengan sendirinya petani kayu manis yang menjadi anggota kaum atau sukunya akan menjual kayu manis mereka kepada pedagang pengumpul ini. Walaupun petani kayu manis yang menjadi anggota kaumnya atau sukunya akan memiliki daya tawar menawar (bargaining) yang lemah, tetapi ini adalah kewajiban sosial (ekonomi moral) yang harus dijalani oleh petani kayu manis. Sering dalam transaksi antara pedagang pengumpul pasar nagari dengan petani kayu manis yang memiliki hubungan kekerabatan ini melakukan pembelian, langsung di kebun-kebun petani kayu manis. Realitas ini memperlihatkan dalam transaksi antara pedagang dan petani kayu manis telah terjadi "permainan aspek ruang dan waktu" yang dilakukan oleh pedagang.

\section{PENUTUP}

1. Mengakar secara historis kepada aktifitas perdagangan di pasar nagari, terutama Patron dengan Klien pedagang komoditi ekspor.

2. Memiliki jaringan klientisasi yang luas dalam menguasai bisnis, memiliki kemampuan membangun resiprositas untuk memperkuat asuransi sosial dengan mitra bisnis.

3. Jaringan bisnis Patron dan Klien pedagang di pasar nagari yang memperdagangkan tanaman eksport dapat dijadikan basis untuk mengembangkan industri pengolahan produk pertanian yang pasarnya terbuka lebar di ASEAN dan China.

4. Terciptanya jaringan klientisasi kelompok bisnis sampai ke pasar nagari dapat menjadi cikal bakal untuk membentuk jaringan bisnis Minangkabau untuk bersaing dengan jaringan bisnis China, dalam memanfaatkan peluang investasi yang diberikan pemerintah Sumatera Barat. 
5. Dengan kemampuan resiprositas dan asuransi sosial yang dimiliki selama ini, dapat membuat keterkaitan bisnis (business leakage) dengan kelompok-kelompok bisnis di sepanjang koridor Sumatera.

\section{DAFTAR PUSTAKA}

Babbie, E, (2004). The Practice of Social Research $\left(10^{\text {th }}\right.$ Edition), Wadsworth /Thomson Learning, Belmont, USA.

Creswell, J. W, (1995). Research Design: Qualitative and Quantitative Approaches, Sage Publications, London.

Damsar, (1997), Sosiologi Ekonomi, PT. Raja Grafindo Persada, Jakarta. , (1998). "Fleamarket" in A German Town; A Study in Economic Sociology, Dissertation, Fakultat fur Soziologie der Universitat Bielefeld, Germany.

, (2005). Tanah Ulayat dan Ketahanan Ekonomi Sosial Budaya Masyarakat Minangkabau, Prosiding Seminar, Balitbang Pertanian dan Yapadi Indonesia, Jakarta.

Padang. , (2005). Sosiologi Pasar, Laboratorium Sosiologi FISIP, Unand, , (2006). Sosiologi Uang, Andalas University Press, Padang.

Dewey, A, (1962). Peasant Marketing in Java, the Free Press of Glencoe, inc, USA

Dobbin, C. (1983). Islamic Revivalism in A Changing Peasant Economy; Central Sumatra, 1784-1847, Curzon Press, London.

, (1992). Kebangkitan Islam dalam Ekonomi Petani yang Sedang Berubah; Sumatera Tengah, 1784-1847, Seri INIS, Julid XII, INIS, Jakarta.

Effendi, N. (1999). Minangkabau Rural Markets: Their System Rules and Function in the Market Community of West Sumatra, Indonesia, Dissertasi, Fakultat fur Soziologie der Universitat Bielefeld, German.

Geertz, C, (1963). Peddlers and Princes, the University of Chicago Press, Chicago and London. , (1977), Penjaja dan Raja; Perobahan Sosial dan Modernisasi Ekonomi di Dua Kota Indonesia, PT. Gramedia, Jakarta. , (1983). Involusi Pertanian: Proses Perubahan Ekologi di Indonesia, Jakarta, Bharata Karya Aksara. 
Graves, Elizabeth, (1981). The Minangkabau Response to Dutch Colonial Role in the Ninetenth Century (Monograph Series) No. 60, Cornell University, Ithaca, New York.

Guba, E. G dan Yvonna S. Lincoln, (1994). Competing Paradigms in Qualitative Research in Norman, K. Denzin and Yvonna S. Lincoln (Eds), Handbook of Qualitative Research, SAGE Publications, London.

Haddad, L. (1991). Gender and Poverty in Ghana: A Descriptive Analysis of Selected Outcomes and Process, IDS Bulletin 22 (1), 5-6. 